\title{
A STUDY OF FORMULATION OF SOFTWARE TEST METRICS FOR INTERNET BASED APPLICATIONS
}

\author{
Manjeet Kumar ${ }^{1}$ and Dr.Rabins Porwal ${ }^{2}$ \\ ${ }^{1}$ Mewar University, Rajasthan, India \\ ${ }^{2}$ ITS, Mohan Nagar, Ghaziabad, India
}

\begin{abstract}
The continuous use of the internet for day to day operations by businesses man, private sector and government has created a great demand for internet applications. In such kind of application web server/application server plays vital role. One of the techniques is to test the functionality of web applications affect user session data received from the web servers. This technique automatically generates test cases on the behalf of user profiles. The contribution of this paper is the internet application of concept analysis for clustering user sessions has been reduced. We have completely automated the process from user session receive and also reduction through replay. In this paper we propose a concept analysis for internet application and also present a tool Ranorex for the same. In order to execute test case we have a model for data retrieval. Web application is using in different areas like, medical, insurance, banking etc.
\end{abstract}

\section{KEYWORDS}

Software Test Metrics, WWW, E-business, V\&V

\section{INTRODUCTION}

Web applications contribute a very big audience and execute in very large network. If we really look at that an Internet application runs in its desired production platform, we have so many parameters against product quality. Markets are growing very fast so the company learn latest strategies from the market and probably implement it[1]. Technology is changing very fast so the incompatibilities between software is very common[3,4]. If we talk about testing there are so many challenges in testing phase[6]. Internet software that is updated automatically.

$>$ If we look at testing so load and security testing are more vital and more difficult[6].

$>$ Another testing challenge is the evaluation of existing technology[4] and evolution of new technology and also constraints. All updation can take place from home server to application server.

This research paper give a proposal for how one can measure of infrastructure for test metrics for the internet/intranet applications. We end the paper by proposing a framework for measuring Internet related metrics of the software. 
Electrical \& Computer Engineering: An International Journal (ECIJ) Volume 4, Number 3, September 2015

\section{ABBREVIATIONS}

\begin{tabular}{|c|c|c|c|}
\hline Keyword & Description & Keyword & Description \\
\hline LOC & Lines of code & RITUP & $\begin{array}{l}\text { Ratio of invalid unprocessed transactions to total } \\
\text { no. of transactions }\end{array}$ \\
\hline $\mathrm{CC}$ & Code complexity & ATT & $\begin{array}{l}\text { Average time taken to complete a business } \\
\text { transaction }\end{array}$ \\
\hline URS & Unreachable statements & TRI/D & $\begin{array}{l}\text { Time taken to retrieve different } \\
\text { images/documents of different sizes }\end{array}$ \\
\hline VDNU & $\begin{array}{l}\text { Variables declared but never } \\
\text { used }\end{array}$ & TOD & $\begin{array}{l}\text { Time taken to open any document (using } \\
\text { different viewers) }\end{array}$ \\
\hline ITDPR & $\begin{array}{l}\text { Inconsistent type declaration } \\
\text { in parameters and return } \\
\text { values }\end{array}$ & TNWP & $\begin{array}{l}\text { Time Taken to navigate through different web- } \\
\text { pages }\end{array}$ \\
\hline RVFNU & $\begin{array}{l}\text { Return values of function } \\
\text { never used }\end{array}$ & TRNC & $\begin{array}{l}\text { Time taken to Recover to Normal condition on } \\
\text { excess load/stress }\end{array}$ \\
\hline $\mathrm{SC}$ & Statement coverage & $\mathrm{DTR} / \mathrm{MC}$ & Date Transfer Rate/Memory Consumption \\
\hline $\mathrm{BC}$ & branch coverage & $\mathrm{DDR} / \mathrm{CB}$ & Delivered data rate (Content bytes) in KB/sec. \\
\hline $\mathrm{CC}$ & Condition coverage & $\mathrm{MC} / \mathrm{C}$ & Memory consumption by a DLLs/components \\
\hline $\mathrm{PC}$ & Path Coverage & CPUT & \%CPU time taken by the server (Processor time) \\
\hline BOOC & $\begin{array}{l}\text { Boolean Operand/ Operator } \\
\text { Coverage }\end{array}$ & PLT & Page Load Time for different pages \\
\hline $\mathrm{DC}$ & Decision Coverage & NOF & No. of times call to the function made \\
\hline $\mathrm{LC}$ & Loop Coverage & NOP & No. of transactions processed per second \\
\hline \multirow[t]{2}{*}{ FDNU } & $\begin{array}{l}\text { Function Declared but never } \\
\text { used }\end{array}$ & RTP & $\begin{array}{l}\text { Ratio of transactions processed to total no. of } \\
\text { transactions }\end{array}$ \\
\hline & & RITP & $\begin{array}{l}\text { Ratio of invalid transactions processed to total } \\
\text { no. of transactions }\end{array}$ \\
\hline
\end{tabular}

\section{SOFTWARE TEST Metrics IN INTERNET APPLICATIONS}

There are three reasons for test metrics for internet application.

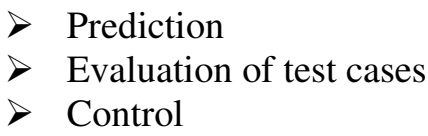

If we really look at the test metrics program then test metrics program consists of five steps [7]:

$>$ Identify business-oriented goal

$>$ Create test metrics

$>$ Collection historical data

$>$ Automate procedures

$>$ Use metrics in decision making capability.

Let us take an example for naïve user experience depends on how much fast they can get data from the source to the destination[7]. If we talk about test metrics then very much required parameter is throughput and it can be defined as the how much data you can transfer in one 
Electrical \& Computer Engineering: An International Journal (ECIJ) Volume 4, Number 3, September 2015

second from source to destination[3,4]. In such case historical data plays important role for performance. Other parameter is bandwidth usage.

On the basis of above a decision should be made on either increasing or decreasing the flowing video content on the dynamic web site[8,10]. If we look at the quality product so TQM process should be included in each step and quality product consists of following types of measurements-

$>$ Measures of test suite complexity

$>$ Measures of test cases

$>$ Measures of release guidelines

\section{TyPES Of TEST METRICS}

We have different kinds of standard test metrics which are suppose to be applied for quality software.

Fig.1 shows the methodology for generating software test metrics for Internet applications.

$\begin{array}{llll}\text { DNPUT } & \text { AC TIVITY } & \text { BENTITS }\end{array}$
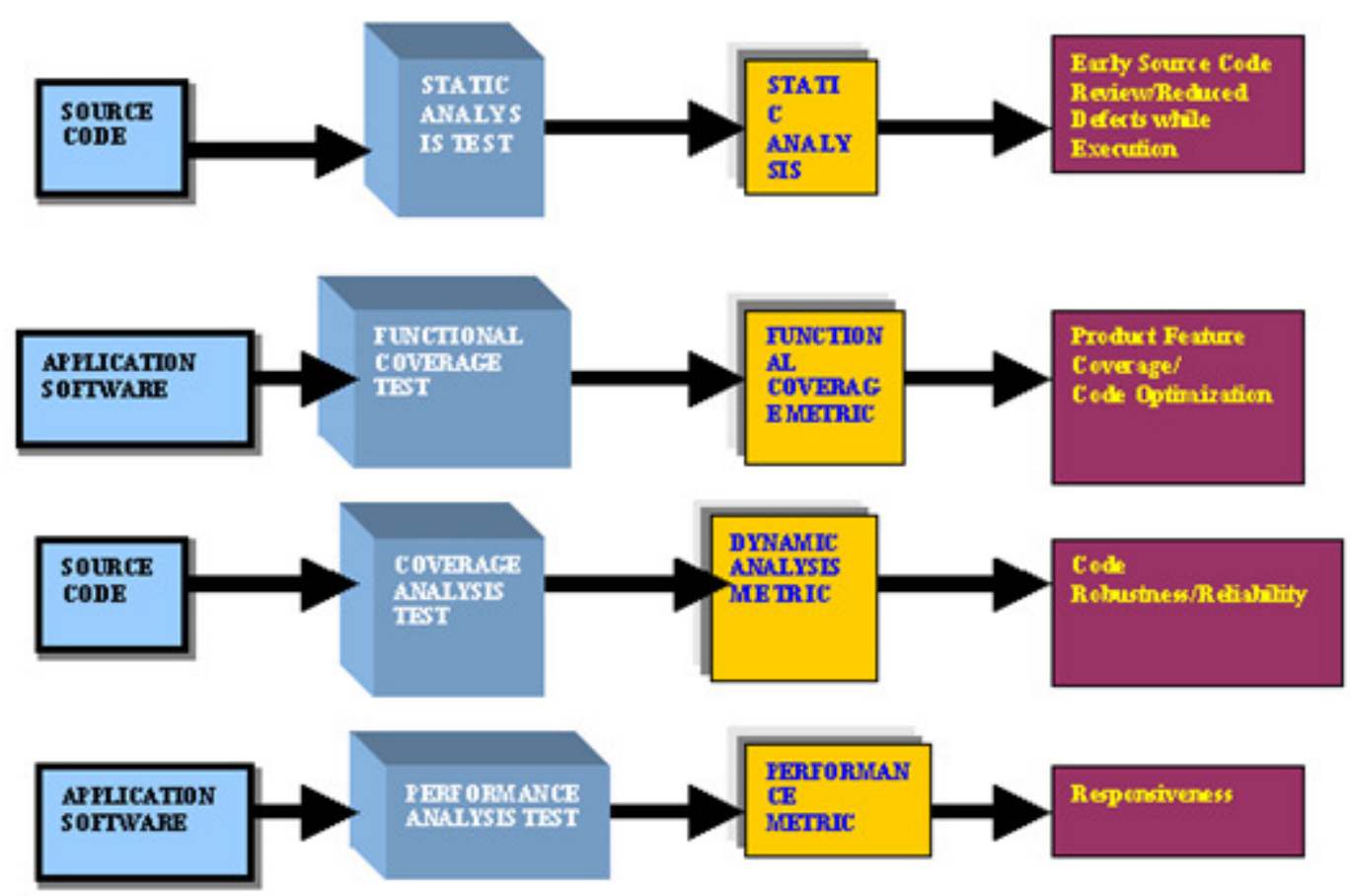

Fig.1: The V\&V Methodology to generate software test metrics for Internet applications 


\subsection{Static Analysis Test Metrics}

The objective of static analysis test metrics is find error in the existing code.If we talk about static testing then developer is able to check errors[3,5]. The same thing can be contributed about quality product. In this scenario error situations are quickly detected[2]. This testing is needed to ensure software fulfillment the existing standards. Let us take an example tracking code complexity is needed for for finding errors. This is well accepted. In such scenario complexity metrics like McCabe's Cyclomatic Complexity are included[5]. If we have a module which is very complex it should be testing very seriously and get the desired outcome. Error situation can be one of them-

Syntax error and deviations from existing standards

Problems in control flow and data flow.

A table below is given for static analysis test metrics.

Table 1.0: Static Analysis Test Metrics

\begin{tabular}{|c|c|c|c|c|c|c|c|}
\hline $\begin{array}{l}\text { CLASS } \\
\text { NAME }\end{array}$ & $\begin{array}{l}\text { FUNCTION/PROCEDU } \\
\text { RE NAME }\end{array}$ & $\begin{array}{l}\text { LO } \\
\text { C }\end{array}$ & $\mathrm{CC}$ & US & $\begin{array}{l}\mathbf{V N} \\
\mathbf{U}\end{array}$ & $\begin{array}{l}\text { IT } \\
\text { D }\end{array}$ & RVNU \\
\hline & & & & & & & \\
\hline & & & & & & & \\
\hline
\end{tabular}

The parameters in above metrics will differ from tool to tool[4]. The test metrics complexity may be either Halstead or McCabe's which is totally depend on the complexity selected by the end user[4] when run the tool. Apart from it it also observed that some more metrics parameters are to be required using the software like McCabe Visual Test Tool.

\subsection{Functional Test Metrics}

Functional Testing of web applications is done to ensure that the input conditions according to the business rules work properly and to check that output conditions are verified against the expected output conditions[12]. It ensures that every function described in the specification is tested and that every function tested is described in the specification[7]. A requirement traceability matrix is a handy tool here. Functionality test metrics could be derived from Scenario Testing and Functional Coverage Testing[7].

\subsubsection{Scenario Testing}

Scenario testing is applicable for determine the status of a web application. The consistency and reliability of E-business systems is based on following parameters-

$>$ First of all the rate of application change from text content to video feature upgrade increases automatically.

$>$ Second if we talk about E-business systems which are suppose to be implemented in mix of platforms/technologies where three entities are involved for the transaction. 
Electrical \& Computer Engineering: An International Journal (ECIJ) Volume 4, Number 3, September 2015

Finally but not last the numbers of end users which are suppose to be connected with an E-business system.

\subsubsection{Function Coverage Testing}

This kind of testing is done for functional coverage to find which methods are never called. If we talk about business scenario then the usage pattern can use for dynamic web site[5]. Each pattern can distribute the numbers of end users among the business cases. We are considering purchase cycle as an example over here[5]. The purchasing over the internet we need to test for the complete purchase cycle:

$>$ Placing an order

$>$ Processing

$>$ Canceling an order

$>$ Checking the status of an order

$>$ Changing the shipping information

The objective is to test the application against each use case.

Table 2.0: Functional Test Coverage Metrics

\begin{tabular}{|c|c|c|c|c|}
\hline $\begin{array}{c}\text { FUNCTIONALI } \\
\text { TY }\end{array}$ & USE & \multicolumn{1}{c|}{ FUNCTION } & NOF & FDNU \\
\hline 1 & & & & \\
\hline 2 & & & & \\
\hline
\end{tabular}

Functional coverage index $=$ No. of functions $/$ Total No. of use case scenarios $\%$ Functional coverage $=$ No. of functions covered per use case $/$ Total No. of functions

\subsection{Dynamic Test Coverage Metrics}

This kind of testing is used for obtaining how much code is being tested. It does not mean that it is not useful. It is useful to have measures of how completely the code is tested[6,9]. Code coverage is the test metrics used in such cases.

The main calculated coverage measures are:

Statement coverage, Branch coverage, Procedure coverage, Path Coverage[13]

Boolean Operand and Operator Coverage, Decision Coverage, Loop Coverage[9]

The $\%$ Decision Coverage defined as the number of decision outcomes in a module[5]. 
Electrical \& Computer Engineering: An International Journal (ECIJ) Volume 4, Number 3, September 2015

$>$ The $\%$ Condition Coverage defined as the number of condition outcomes for each decision in a module.

Table 3.0: Dynamic Test Coverage Metrics

\begin{tabular}{l|l|l|l|l|l|l|l|}
\hline MODULE & DYNAMIC ANALYSIS METRICS PARAMETERS \\
NAME & $\%$ SC & $\%$ & $\%$ CC & $\%$ & $\%$ BOC & $\%$ DC & $\%$ LC \\
& BC & \multicolumn{1}{c|}{ PC } & \\
\hline & & & & & & & \\
\hline & & & & & & & \\
\hline
\end{tabular}

\subsection{Performance Test Metrics}

The internet is one of the growing technologies in the world. Organization is using web technology in the form of internet, intranet and Extranet applications to carry their products and information is suppose to be provide to their customers.. In some cases it has been observed that web server is loaded due to millions so in this scenario we required to do a load and stress testing. For example a client/server 3-tier architecture contains a client system and a server system, data base server, all of them are responsible for data processing. On the internet, the client is the browser for sending request and server for response with the coordination of data base server likr oracle $10 \mathrm{~g}$. The web server processed all the requests through URLs from the client. Following are the methods for performance testing:

$>$ Modem Simulation

Multiple URLs/URIs for dynamic Web Site

Load Simulation

Such kind of testing can take place with WebLoad $^{\mathrm{TM}}$, Astra QuickLoad ${ }^{\mathrm{TM}}$ etc

Table 4.1: Performance Test Metrics

\begin{tabular}{|c|c|c|c|c|c|c|c|c|c|}
\hline Test & \multicolumn{9}{|c|}{ In case of web-applications with /without payment interface } \\
\hline $\begin{array}{c}\text { Modem } \\
\text { Speed }\end{array}$ & $\begin{array}{c}\text { TRI/ } \\
\mathrm{D}\end{array}$ & TOD & TNWP & $\begin{array}{c}\text { TRN } \\
\text { C }\end{array}$ & $\begin{array}{l}\text { DTR } \\
/ \mathrm{MC}\end{array}$ & $\begin{array}{c}\mathrm{DDR} / \mathrm{C} \\
\mathrm{B}\end{array}$ & $\begin{array}{c}\mathrm{MC} / \\
\mathrm{C}\end{array}$ & $\%$ CPUT & PLT \\
\hline $14.4 \mathrm{kbps}$ & & & & & & & & & \\
\hline $28.8 \mathrm{kbps}$ & & & & & & & & & \\
\hline $56.6 \mathrm{kbps}$ & & & & & & & & & \\
\hline $64 \mathrm{kbps}$ & & & & & & & & & \\
\hline $128 \mathrm{kbps}$ & & & & & & & & & \\
\hline
\end{tabular}


Electrical \& Computer Engineering: An International Journal (ECIJ) Volume 4, Number 3, September 2015

Table 4.2: Performance Test Metrics

In Case of Applications with payment interface
\begin{tabular}{|l|c|c|c|c|c|}
\hline Test Condition & \multicolumn{5}{|c|}{ No. of concurrent users per second } \\
\hline $\begin{array}{l}\text { NOP/RTP } \\
\text { RITP/RITUP/AT } \\
\text { T }\end{array}$ & $\begin{array}{c}\text { Minimu } \\
\mathrm{m}\end{array}$ & $\begin{array}{c}\text { Avera } \\
\text { ge }\end{array}$ & $\begin{array}{c}\text { Maximu } \\
\mathrm{m}\end{array}$ & $>$ Maximum Users & Modem Speed \\
\hline & & & & & \\
\hline & & & & & $14.4 \mathrm{kbps}$ \\
\hline & & & & & $28.8 \mathrm{kbps}$ \\
\hline & & & & & $56.6 \mathrm{kbps}$ \\
\hline & & & & & $64 \mathrm{kbps}$ \\
\hline
\end{tabular}

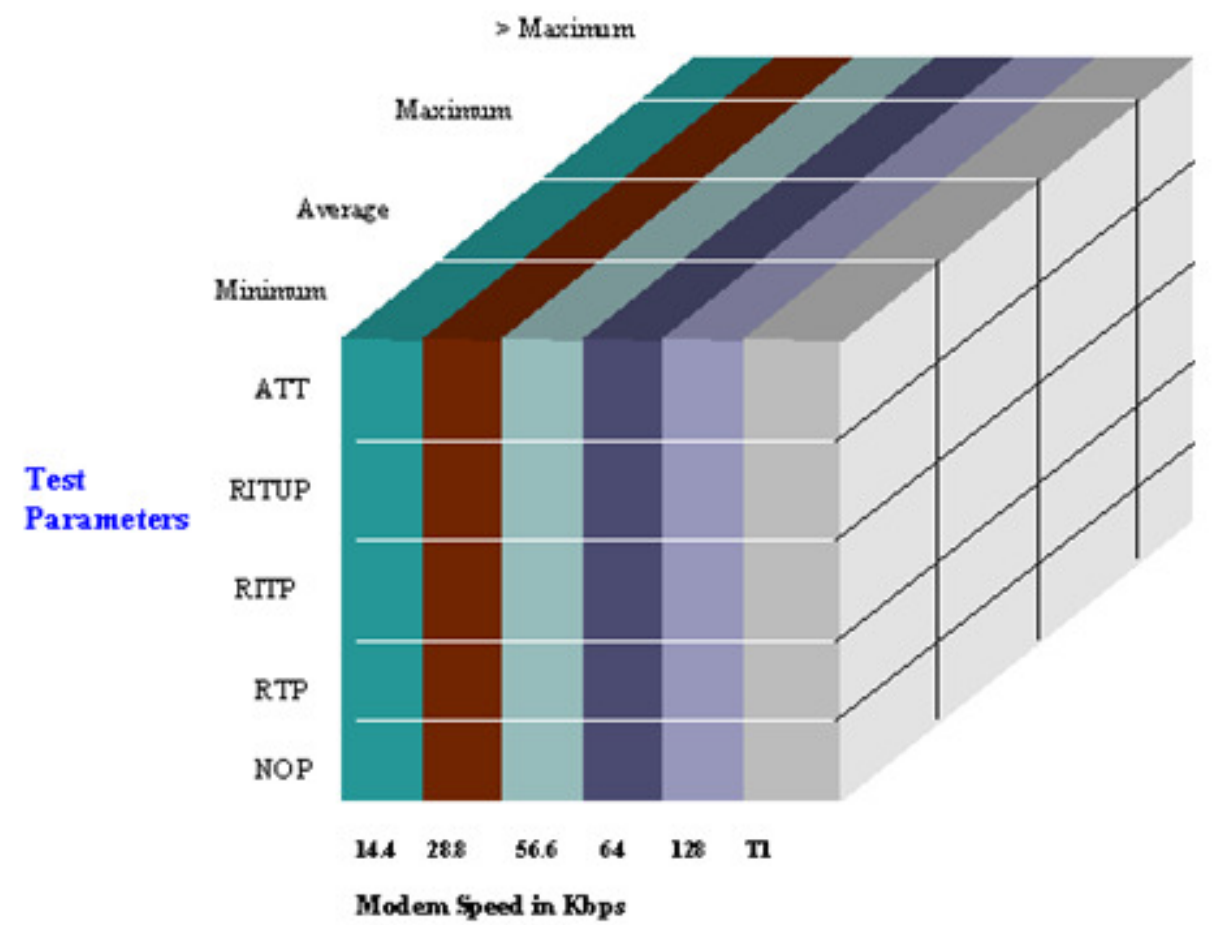

Fig.2: 3-dimensional representation of Performance Test Metrics for Internet Applications

\section{CONCLUSION}

Metrics and their use is based on application. This methods required periodic reevaluation of the metrics. Metrics are basically for collection and simulation of the real life application so they are indicators for internet application. It is very much required to understand the applicability of formulating software test metrics as the key to product improvement in the Internet space. Software test metrics is for monitoring and controlling the quality of the product . Interpretation of the resulting testing metrics is suppose to be present in tabular form and to observe changes whenever is required. 
Electrical \& Computer Engineering: An International Journal (ECIJ) Volume 4, Number 3, September 2015

\section{REFERENCES}

[1] Abbot 0.13.1, 2008. http://abbot.sourceforge.net/.

[2] Glenn Ammons, Rastislav Bodik, and James R. Larus. Mining specifications. In Proc.29th ACM SIGPLAN-SIGACT Symposium on Principles of Programming Languages,pages 4-16, 2008.

[3] Paul E. Ammann, Paul E. Black, and William Majurski. "Using model checking to generate tests from specifications". In Proc. 2rd IEEE International Conference on Formal Engineering Methods, page 46, 2010.

[4] G. Alonso, F. Casati, H. Kuno, and V. Machiraju. "Web Services Concepts, Architectures and Applications Series: Data-Centric Systems and Applications”. Addison-Wesley Professional,, 2009.

[5] David Abramson, Ian Foster, John Michalakes, and Rok Socic. Relative debugging: a new methodology for debugging scientific applications. Communications of the ACM,39(11):69-77, 2010 .

[6] Ken Arnold, James Gosling, and David Holmes. "The Java Programming Language.Addison-Wesley Longman Publishing Co., Inc., 2010”.

[7] Agitar Agitatior 2.0, Novermber 2004. http://www.agitar.com/.

[8] Dorothy M. Andrews. Using executable assertions for testing and fault tolerance. In Proc. the 9th International Symposium on Fault-Tolerant Computing, pages 102-105,2010.

[9] Tony Andrews, Shaz Qadeer, Sriram K. Rajamani, Jakob Rehof, and Yichen Xie. Zing:A model checker for concurrent software. In Proc. 6th International Conference on Computer Aided Verification, pages 484-487, 2007.

[10] Alberto Avritzer and Elaine J. Weyuker. Deriving workloads for performance testing.Softw. Pract. Exper., 26(6):613-633, 2003.

[11] Thomas Ball. A theory of predicate-complete test coverage and generation. Technical Report MSRTR-2004-28, Microsoft Research, Redmond, WA, April 2004.

[12] Clark W. Barrett and Sergey Berezin. CVC Lite: A new implementation of the cooperating validity checker. In Proc. 16th International Conference on Computer Aided Verification, pages 515-518, July 2004.

[13] Dirk Beyer, Adam J. Chlipala, and Rupak Majumdar. Generating tests from counterexamples. In Proc. 26th International Conference on Software Engineering, pages 326-335, 2004.

[14] Timothy A. Budd, Richard A. DeMillo, Richard J. Lipton, and Frederick G. Sayward.Theoretical and empirical studies on using program mutation to test the functional correctness of programs. In Proc. 7th ACM SIGPLAN-SIGACT Symposium on Principles of Programming Languages, pages 220233, 2006.

[15] Kent Beck. Extreme programming explained. Addison-Wesley, 2008.

[16] Kent Beck. Test Driven Development: By Example. Addison-Wesley, 2006.

[17] Boris Beizer. Software Testing Techniques. International Thomson Computer Press,2003.

[18] Gilles Bernot, Marie Claude Gaudel, and Bruno Marre. Software testing based on formal specifications: a theory and a tool. Softw. Eng. J., 6(6):387-405, 2004.

[19] Thomas Ball, Daniel Hoffman, Frank Ruskey, Richard Webber, and Lee J. White. State generation and automated class testing. Software Testing, Verification and Reliability,10(3):149-170, 2005.

[20] Robert V. Binder. Object-oriented software testing. Commun. ACM, 37(9):28-29, 2003.

\section{AUTHOR}

Manjeet Kumar received MCA. degree in Computer Science from K.N.I.T Sultanpur, (2004), and M-Tech degree in IT(2010) from Karnatika University. At the moment he is Ph.D. scholar at Mewar University,Rajasthan. His research interest includes Automated software testing,Web technology. Email: manjeet 2005@gmail.com,

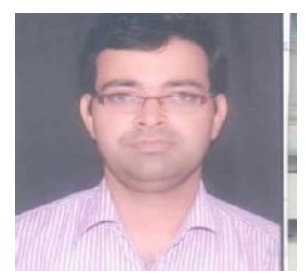

